\title{
Designing Educational Programs for Older Adults 1
}

\section{Carolyn Wilken²}

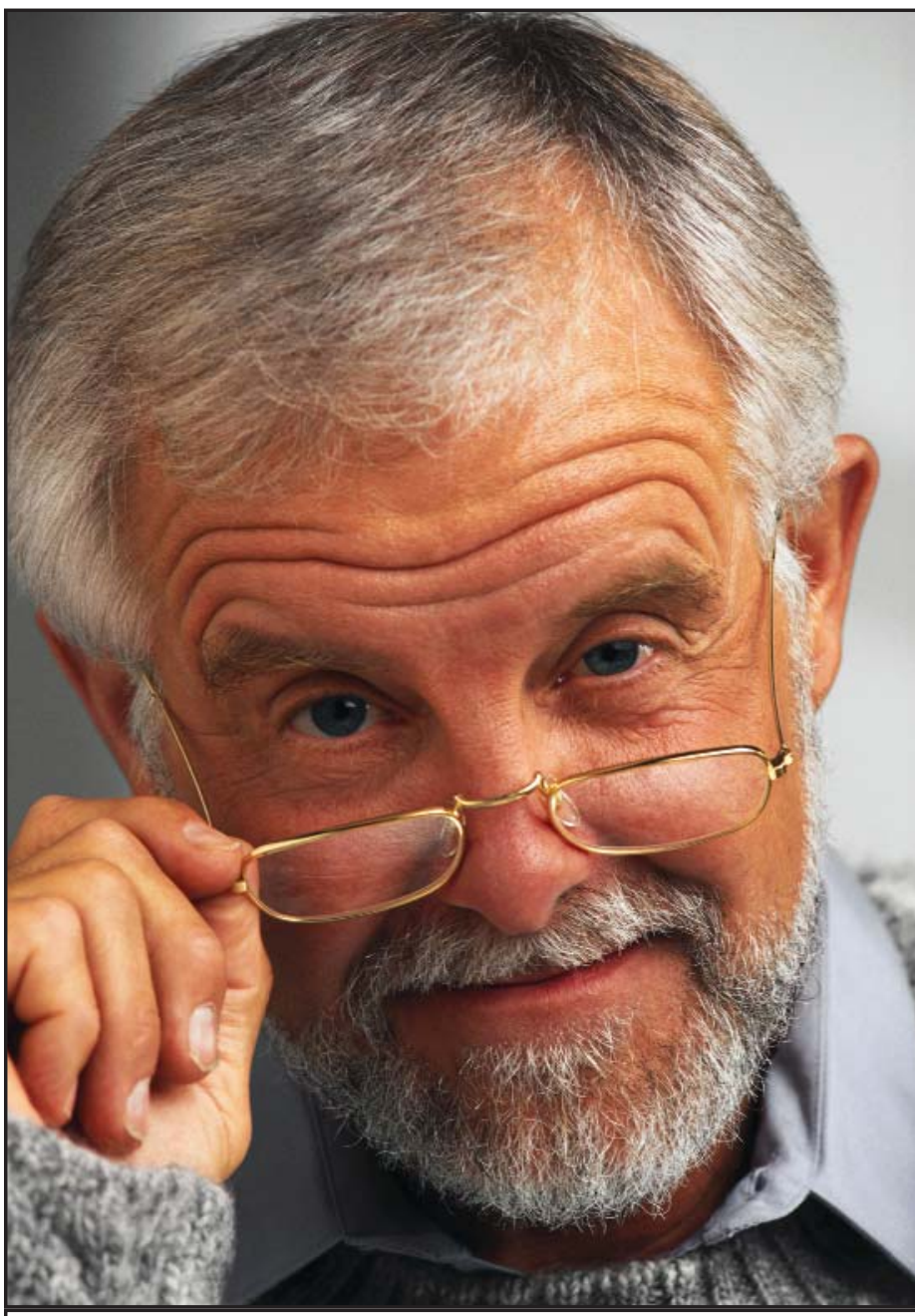

1. This document is FCS2216 FY631, one of a series of publications from the distance education in-service "Aging in the 21st Century," coordinated by Carolyn Wilken, PhD, MPH, Department of Family, Youth and Community Sciences, UF/IFAS. First published: September 2003. Reviewed by Candice King, formerly coordinator of Research Programs, Institute on Aging. University of Florida, Gainesville, 32611.

2. Carolyn Wilken, PhD, MPH, Associate Professor, University of Florida, IFAS, Department of Family, Youth and Community Sciences, and University of Florida Institute on Aging,

Gainesville, 32611.

\section{Aging in the 21st Century}

According to the U.S. Census Bureau, by the year 2050 the nation's elderly population will more than double to 80 million, and the more frail, over-85 population will quadruple to 18 million.

Currently, Florida ranks first in the United States in the percent of the population who is full-time and seasonal residents over the age of 65 . Older Floridians, their families and communities face a myriad of issues related to aging.

Aging in the 21st Century is an eight-topic program that addresses issues such as:

- health and medical care

- family relationships

- economic concerns

- caregiving

- home modifications

- retirement

- nutrition and diet

Institute on Aging core faculty from the Colleges of Medicine, Nursing, Health Professions, and Liberal Arts and Sciences joined Extension faculty from IFAS as educators for this series.

\section{Professional audiences}

The Institute of Food and Agricultural Sciences is an equal opportunity/affirmative action employer authorized to provide research, educational information and other services only to individuals and institutions that function without regard to race, color, sex, age, handicap or national origin. For information on obtaining other extension publications, contact your county Cooperative Extension Service office. Florida Cooperative Extension Service/Institute of Food and Agricultural Sciences/University of Florida/Christine Taylor Waddill, Dean. 


\section{What You WILL LEARN}

- MARKeting: how to use the

media, information centers and community partners to effectively reach older adults

Location \& Timing: key points to consider when choosing the best location and time for your program

Presentation: how to use visual and verbal communication to successfully share information with older adults

\section{MARKETING TO Older Adults}

One of the most important steps in designing a successful program is choosing how to most effectively reach your target audience.

Among the options to consider when targeting older adults are:

(1) traditional media,

(2) information centers, and

(3) community partners.

\section{Traditional Media}

Although very effective in reaching the older population, television is quite expensive and unless your program has a large budget, you should consider radio.

Radio is very effective in reaching older adults and considerably less expensive. Many local radio stations sponsor community announcements at no cost.

The Federal Trade Commission
(FTC) requires every television and radio station to contribute airtime for public service announcements (PSAs). Contact the station manager for information about their policies and procedures regarding PSAs.

Newspapers are also a good way to get your message out. Most local newspapers have weekly community calendars or weekly sections especially designed for the retirement community.

Contact your local newspaper to find out what opportunities are available to market your program. Be sure to keep the newspaper informed about future programs.

\section{Information Centers}

Your best ally in targeting older adults is your own community. Use your community centers, organizations and faith-based communities

\section{LOCATION}

When choosing the location for your program consider:

- Transportation: Where does your audience live? How will they travel to your program?

- Accessibility: How many handicap parking spots will you need? Are there enough rest room facilities to accommodate the size of your audience?

- Room arrangement: Are the seats comfortable enough for the time your audience will be sitting?

Think about what your audience will be doing during your program and arrange the room accordingly. as information centers. Older adults are often very involved within the community, so make use of the bulletin boards and newsletters offered by these organizations to reach your target audience.

Also remember to BE YOUR OWN INFORMATION CENTER. Word of mouth is still one of the most effective ways to get people interested in a program.

\section{Community Partners}

Community partners are great resources for recruiting older adults to your programs. Consider working with:

- County Cooperative Extension faculty

- Senior Centers' directors

- Area Agency on Aging professionals

- Health care professionals

\&

\section{TIMING}

When choosing the time of your program remember to:

- Avoid early mornings

- Coordinate with other programs: Does the time of your program conflict with other similar programs? Could you 'double' program attendance by coordinating with a similar one?

- Avoid asking participants to get out at night: Does your program end around dinnertime? Is it too dark for driving at the time your program ends?

Think about your audience's routine and schedule your program accordingly. 


\section{Presenting to Older Adults}

Now that you have decided how to best reach your audience and have chosen a location and time, you can focus on the presentation of your program.

There are two main elements in designing a presentation: verbal and visual. Each element needs to complement the other in order for the presentation to be successful.

\section{Verbal}

To get the important points of your presentation across, it is essential that your audience listens to and understands the message you are trying to convey.

Below is a list of important points to consider when talking to an older audience:

- Speak clearly, slowly and directly to your audience.

- Rephrase important points.

- Consider vocabulary and avoid technical terms.

- Repeat questions and comments for the audience.

- Control background noise.

- Use a microphone if needed and check it out with hearing aid users.

- Use humor!

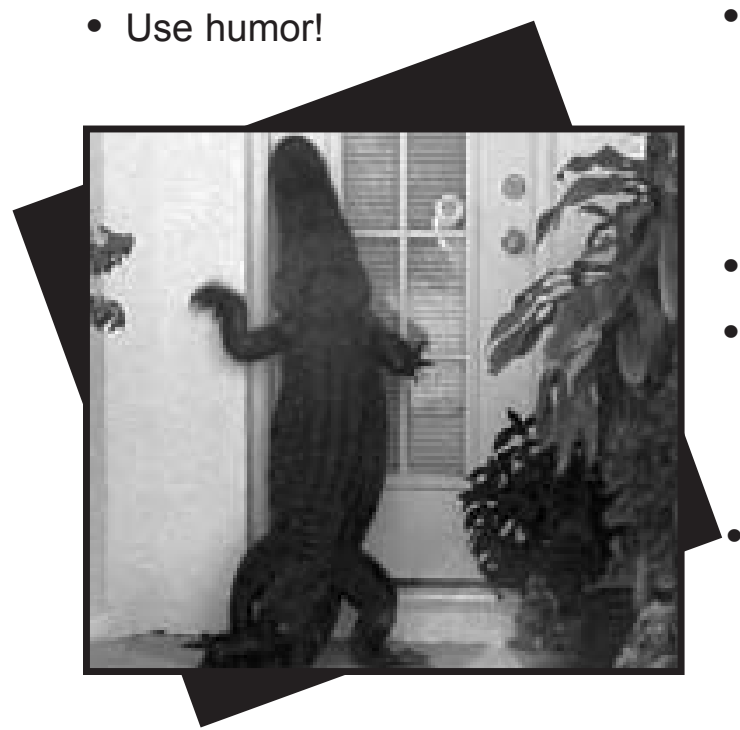

Visual

Always use visuals to supplement verbal communications. The visual aspect of a presentation involves both projection

(PowerPoint or PDF presentations, overhead, etc.) and print publications (handouts, brochures, flyers, etc.)

It is important that you consider each aspect individually as well as part of one unified presentation. Projections and print although often very similar, demand different preparation.

\section{Print Publications}

Below are some factors to consider when designing supplemental print materials for your program:

- Use dark on light for print since it is easier to read. Use light on dark on small sections if you want to give a dramatic look to your publication. It is important however, to always maximize the contrast between paper and ink.
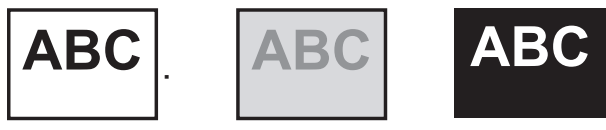

- Use a standard format for your publication. The combination of different fonts, colors and elements often distracts from your main message.

- Maximize white space.

- Use columns. They allow for more white space and they help guide your reader through the publication.

Limit the use of ALL CAPS. Lower and upper case words are much easier to read.
- Use short lines - 3 to 4 inches.

- Avoid slick paper. It is hard to turn the pages.

- Avoid shiny paper. The reflections make it hard to read.

\section{What Font To Use?}

No matter what you do, avoid using elaborate fonts such as Monotype Corsiva or any other script style font. They are hard to read and will distract your audience.

\section{Projecting}

Sans-Seriff fonts (those without feet) are usually best when projecting. The serifs (feet) can be distracting on the screen. Also consider bold faced type when projecting.

Examples of projection fonts:

- Arial

- Century Gothic

- Tahoma

- Verdana

PRINT

Serif fonts are usually best to use for printing. The little 'feet' guide the reader's eyes along the paper.

Examples of print fonts:

- Bookman Old Style

- Book Antigua

- Times New Roman

- Courier New

- Georgia 


\section{Projections}

Below are some factors to consider when you design a program that will be projected or shown on a screen.

- Use light on dark for projections. It reduces the glare of stark background. Remember: always maximize contrast!
- Use as much light as possible in your room.

- Use graphs and charts that are clean and as large as possible. Label them clearly.

- Keep information on a slide to a minimum.

\section{ChOOSE FOR YOURSELF}

$80 \%$ of what they see

Use visuals to supplement verbal

communications

Use slides/pp with as much light

as possible

Consider bold faced type

Label charts and graphs clearly

- Keep information on slide to

minimum

- Provide plenty of white space

\section{$80 \%$ of what they see}

- Use visuals to supplement verbal communications

- Consider bold faced type

- Keep information on slide to minimum
PUBLICATIONS IN THIS SERIES:

The Future of Aging is Florida Jeffrey Dwyer, PhD

- Safe Return

Meredeth Rowe, RN, PhD

Financial Issues

Jo Turner, PhD, CFP

Elder Nutrition

Linda Bobroff, PhD, RD, LD/N

- Fall Prevention

Kristen Smith, MPH

Family Relationships in an Aging Society

Terry Mills, PhD

Adapting the Home

Pat Dasler, MA, OTR/L

- Developing Educational

Programs for Older Adults

Carolyn Wilken, PhD, MPH

Aging in the 21st Century is cosponsored by the University of Florida Institute of Food and Agricultural Sciences (UF/IFAS) Department of Family, Youth and Community Sciences; and the College of Medicine's Institute on Aging. It is supported by a grant from the Associate Provost for Distance, Continuing and Executive Education, Dr. William Riffee.
Wilken C. (1992). Designing extension publications and presentations to be seen and heard by all. Journal of Extension, 30(Summer), 15-17.

Wilken, C. (Summer, 2003). The family life education needs of mid-life and older adults. A review. In Research News You Can Use. Retrieved July 15, 2003 from:

http://fycs.ifas.ufl.edu/research07.htm\#anchor4

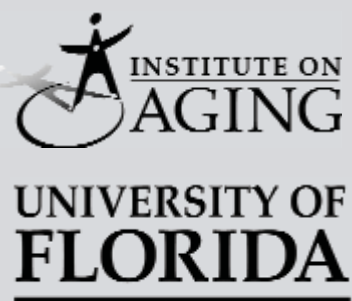

IFAS EXTENSION 